\title{
埃可病毒11型利用双受体CD55和FcRn侵染细胞的 分子结构基础
}

牛胜 ${ }^{1,2 \dagger}$, 刘闯 ${ }^{3 \dagger}$, 刘聪聪 ${ }^{3}$, 刘升 $^{2,5}$, 宋洋 ${ }^{6}$, 张勇 ${ }^{6,7}$, 田文霞 ${ }^{1}$, 赵欣 ${ }^{2,4^{*}}$, 王培毅 $3^{*}$, 高福 $2,4,6^{*}$

1. 山西农业大学动物科技学院, 太谷 030801 ;

2. 中国科学院微生物研究所, 中国科学院病原微生物与免疫学重点实验室, 北京 100101;

3. 南方科技大学冷冻电镜中心, 生物系, 深圳 518055 ;

4. 中国科学院流感研究与预警中心, 北京 100101 ;

5. 中国科学技术大学生命科学学院, 合肥 230026 ;

6. 中国疾病预防控制中心病毒病预防控制所, 北京 102206;

7. 中国疾病预防控制中心病毒病预防控制所, 卫生部医学病毒学和病毒病重点实验室, 世界卫生组织西太平洋区脊髓灰质炎参比实验室, 北京 102206

$\dagger$ 同等贡献

*联系人, E-mail: zhaoxin@im.ac.cn; wangpy@sustech.edu.cn; gaof@im.ac.cn

2019-12-01 收稿, 2019-12-20 修回, 2019-12-23 接受, 2019-12-23 网络版发表

中国科学院B类战略性先导科技专项(XDB29010000)、国家科技重大专项(2018ZX10733403)、国家自然科学基金(81601766)和北京市科技新 星计划(Z191100001119030)资助

摘要 埃可病毒 11 型属于小RNA病毒科, 肠道病毒属, 是B族肠道病毒中的一个重要血清型. 埃可病毒11型可导致 儿童和青少年脑炎和脑膜炎等疾病, 在婴儿和新生儿中导致重症感染甚至致命的病例也时有报道. 此外, 埃可病毒 11型还多次在新生儿和婴幼儿群体中引起暴发性感染，如2019年中国广东省发生的院内感染暴发事件，造成了19 例新生儿的感染和 5 例死亡, 严重威胁人类健康和公共卫生安全. CD55是20世纪 90 年代初发现的部分埃可病毒的 吸附受体, 该受体可以帮助病毒吸附在细胞表面, 但并不能介导病毒完成完整的入侵过程。我们在2019年的研究 中, 发现了人新生儿Fc受体(neonatal Fc receptor, FcRn)是B族肠道病毒的通用脱衣壳受体, 并以埃可病毒 6 型为例解 析了病毒入侵机制. 本研究利用冷东电子显微镜技术, 解析了埃可病毒 11 型在入侵过程中不同 $\mathrm{pH}$ 条件下各阶段的 病毒颗粒结构, 以及病毒与两受体的复合物, 共 10 个原子或近原子水平高分辨率冷冻电子显微镜结构, 并结合表面 等离子共振( surface plasmon resonance, SPR)和脂质体模拟试验等分子水平试验, 系统地阐述了埃可病毒11型利用 CD55和FcRn“双受体系统”入侵细胞的分子机制。埃可病毒11型利用其VP2、VP3结构域与吸附受体CD55的3、4 两个短同源重复(short consensus repeat, SCR)结构域结合, 结合后病毒颗粒不发生变构. 病毒与脱衣壳受体FcRn结 合之后, 开始发生变构, 并可在脂质体膜的辅助作用下释放遗传物质完成脱衣壳. 与埃可病毒 6 型不同的是, 埃可病 毒 11 型结合FcRn之后在中性条件下即可起始变构. 本项研究解析了重要病原埃可病毒11型侵染细胞的分子结构基 础, 并进一步完善了非囊膜病毒的“双受体”入侵模型.

关键词埃可病毒 11 型, 肠道病毒, 冷冻电子显微镜, 入侵, 双受体系统, CD55, FcRn

引用格式: 牛胜, 刘闯, 刘聪聪, 等. 埃可病毒11型利用双受体CD55和FcRn侵染细胞的分子结构基础. 科学通报, 2020, 65: 67-79 Niu S, Liu C, Liu C C, et al. Molecular and structural basis of Echovirus 11 infection by using the dual-receptor system of CD55 and FcRn (in Chinese). Chin Sci Bull, 2020, 65: 67-79, doi: 10.1360/TB-2019-0786 
新发与再发病毒严重危害人类健康, 是全球公共 卫生的严重问题 ${ }^{[1]}$. 近年来, 肠道病毒感染引起的疾病 在美国、欧洲多国、中国等地广泛流行. 埃可病毒 11 型属于B族肠道病毒, 小RNA病毒科, 肠道病毒属. 肠 道病毒是导致人类特别是儿童和青少年传染性疾病的 重要病原之一, 可引起脊髓灰质炎(小儿麻痹症)、手足 口病、疮疹性咽峡炎、儿童病毒性脑炎、脑膜炎等疾 病 $^{[2]}$. 肠道病毒感染部位在肠道, 但发病部位却可以遍 及全身各重要器官, 甚至于中枢神经系统 ${ }^{[2,3]}$. B族肠道 病毒包括埃可病毒(Echovirus)、柯萨奇病毒B等, 可导 致新生儿和青少年病毒性脑炎、脑膜炎、脑膜脑炎等 疾病, 严重时可致命, 且部分病例留有严重后遗症 ${ }^{[2]}$. B 族肠道病毒主要通过粪口传播, 与感染或携带 $\mathrm{B}$ 族肠道 病毒的患者进行密切生活接触以及共用饮食等均可导 致肠道病毒的感染 ${ }^{[2,3]}$.

$B$ 族肠道病毒感染是常见的儿童感染性疾病病因 之一, 多数为隐性感染或轻症, 但亦可导致病毒性脑 炎、脑膜炎等疾病. 除此之外, B族肠道病毒感染还可 导致急性弛缓性痽疾(acute flaccid paralysis, AFP)、非 特异性皮疹、肝炎、肺炎、凝血障碍和手足口病等疾 病 $^{[2,4]}$. 在中国以及世界范围内, 埃可病毒等B族肠道病 毒一直是大部分儿童脑炎、脑膜炎病例的致病病原 ${ }^{[5]}$. 埃可病毒 11 型是埃可病毒中致病力较强的一个血清型, 在中国和世界其他国家肠道病毒的流行病学调查中均 占重要位置. 在中国多个省份中, 埃可病毒 11 型感染病 例在脑炎、急性弛缓性麻痹等病例中均占较大比 例 ${ }^{[5 \sim 7]}$. 值得注意的是, 埃可病毒 11 型还可造成新生儿 和贞幼儿的群体性感染、新生儿院内感染、婴幼儿家 庭性和幼儿园集体感染等 ${ }^{[8 \sim 12]}$. 2019年, 在中国广东省, 由埃可病毒 11 型导致的医院感染暴发事件造成了 19例 新生儿的感染和5例死亡(国卫医函(2019)115号). 目前 埃可等B族肠道病毒均无特异性药物和疫苗, 所以对埃 可病毒 11 型需要更加深人和针对性的研究.

病毒人侵是病毒感染细胞的关键步骤，而宿主细 胞上的受体分子对病毒感染至关重要，正是病毒表面 蛋白与宿主受体的相互作用, 开启了病毒侵染与复制 的过程. 迄今为止, 已经有多种重要的肠道病毒受体被 发现: 如EV-A71等A族肠道病毒的受体有清道夫受体 B2(scavenger receptor B2, SCARB2) ${ }^{[13]}$ 和P-选择素糖蛋 白配体-1(P-selectin glycoprotein ligand-1, PSGL-1) ${ }^{[14]}$ 、 柯萨奇病毒A10等A族肠道病毒的受体KREMEN $1^{[15]}$; C族肠道病毒膌髓灰质炎病毒受体CD155(poliovirus re- ceptor, PVR $)^{[16]}$ 、柯萨奇病毒A21和A24的受体细胞间 黏附分子-1(intercellular adhesion molecule-1, ICAM$1)^{[17,18]}$; D族肠道病毒EV-D68受体细胞间黏附分子-5 (intercellular adhesion molecule-5, ICAM-5)等 ${ }^{[19]}$. B族 肠道病毒中, 发现有柯萨奇B病毒的受体、柯萨奇与腺 病毒受体(coxsackie and adenovirus receptor, CAR)以及 多种 $\mathrm{B}$ 族肠道病毒的通用吸附受体CD55(又称补体衰 变加速因子, decay-accelerating factor, DAF $)^{[20-22]}$. 在最 近的研究中, 本课题组和其他研究团队 ${ }^{[23,24]}$ 发现了新 生儿Fc受体(neonatal Fc receptor, FcRn)是B族肠道病 毒中埃可病毒、柯萨奇 $\mathrm{A} 9$ 和部分新发现的 $\mathrm{B}$ 族肠道病 毒的通用受体, 负责病毒在低 $\mathrm{pH}$ 条件下的基因组释放.

通常情况下, 依据肠道病毒受体的功能, 可以将其 分为两种: (i ) 吸附受体, 如CD55等, 将病毒吸附在细 胞表面, 部分吸附受体会辅助病毒的内吞. 但吸附受体 不会导致病毒变构, 不能帮助病毒完成遗传物质释 放 ${ }^{[23,25,26]}$. (ii ) 脱衣壳受体, 如SCARB2、PVR、

ICAM-1、CAR和FcRn等，与病毒结合后，可以诱导病 毒变构释放遗传物质 ${ }^{[2,23,25,27]}$. 脱衣壳受体通常结合在 肠道病毒表面由VP1衣壳蛋白形成的五重轴周围, 称 为“峡谷区”(canyon)的凹陷部位. 受体结合病毒后可以 诱导位于病毒“峡谷区”底部, 被称为“口袋因子”(pocket factor)的脂质分子释放. “口袋因子”对维持病毒衣壳结 构稳定起重要作用, 它的释放导致病毒衣壳失去稳定 性, 从而起始变构, 随后将遗传物质释放人胞内, 完成 病毒人侵 ${ }^{[14,23,25,27 \sim 32]}$.

本研究团队与Coyne研究团队 ${ }^{[23,24]}$ 的近期研究, $F c R n$ 是包括埃可病毒 11 型在内的部分 $B$ 族肠道病毒的 通用脱衣壳受体. 本课题组在总结前人研究及我们新 近发现 F $\mathrm{Fn}$ 为B族肠道病毒通用脱衣壳受体的基础上, 提出了吸附受体-脱衣壳受体双受体协同作用的生化 与分子机制, 即在中性 $\mathrm{pH}$ 条件下, 病毒结合吸附受体并 完成内吞; 在内吞体酸性 $\mathrm{pH}$ 条件下, 病毒结合驻扎在内 吞体膜上的脱衣壳受体, 释放“口袋因子”, 进而释放遗 传物质. 这些都是以埃可病毒 6 型为模型完成的，其他 型病毒是否采用同样的机制需要进一步的试验验 证 ${ }^{[23]}$. 本研究揭示了埃可病毒 11 型与双受体的结合机 制以及受体诱导病毒脱衣壳的分子机制与结构基础.

\section{1 材料与方法}

( i ) 细胞与毒株. 人横纹肌肉瘤(rhabdomyosarcoma, RD)细胞, HEK293T细胞由中国科学院微生物研究 
所提供，细胞培养于含 $10 \%$ 胎牛血清(FBS，Invitrogen) 和100 $\mathrm{U} / \mathrm{mL}$ 青霉素-链霉素的DMEM(Invitrogen)培养 基中, $5 \% \mathrm{CO}_{2}, 37^{\circ} \mathrm{C}$. 埃可病毒 11 型(SD03-478, GenBank号：MN496161)毒种由中国疾病预防控制中心病 毒病预防控制所提供, 并通过RD细胞扩增病毒.

(ii) 病毒的扩增与纯化. 经单克隆纯化的埃可病 毒 11 型通过RD细胞在 $37^{\circ} \mathrm{C}$ 培养 $24 \mathrm{~h}(\mathrm{MOI} 0.1)$. 收集细 胞上清后, 首先用 $12000 \times g$ 离心 $60 \mathrm{~min}$ 以去除细胞碎片, 而后通过 $140000 \times g$ 超速离心 $2 \mathrm{~h}$ 将病毒沉淀到离心管底 部, 并用磷酸盐缓冲液( phosphate buffer saline, PBS)浸 泡病毒6 h后缓慢重悬. 最后通过 $20 \% \sim 60 \%$ 蔗糖密度梯 度离心进行纯化, 转速 $140000 \times g$ 离心 $4 \mathrm{~h}$ 后, 收集含有病 毒的分层夜, 通过Amicon Ultra-6 $100 \mathrm{kD}$ 浓缩管(Millipore)利用pH 7.4的PBS缓冲液进行浓缩换液. 上述纯化 过程均在 $4^{\circ} \mathrm{C}$ 进行.

（iii）蛋白表达及纯化. FcRn和CD55的蛋白纯化方 法参照我们前期工作进行 ${ }^{[23]}$. 简而言之, 首先将人源 FCGRT编码片段(A16-L282)和CD55编码片段(D35$\mathrm{G} 285$ )插人到pCMV3载体上, 该载体的 $\mathrm{N}$ 端含有人源IL2 信号肽, $\mathrm{C}$ 端有 6 个组氨酸, 酶切位点为 Hind III 和 $B a m \mathrm{H}$ I . 将人源FCGRT和B2M质粒(HG11976-NH, 义 尧神州科技有限公司)共转染人HEK293T细胞后用于 FcRn蛋白表达, 同时将人源CD55质粒转染HEK293T细 胞用于CD55蛋白表达，72和144 h后分别收集细胞上 清, 依次通过NTA色谱层析柱(GE Healthcare)和分子篮 凝胶层析柱Hiload 16/600 Superdex ${ }^{\circledR} 200$ pg column(纯 化FcRn使用, GE Healthcare)以及Hiload 16/600 Super$\operatorname{dex}^{\circledR} 75$ pg column(纯化CD55使用, GE Healthcare)进行 蛋白纯化, 缓冲液为 $\mathrm{PBS}(\mathrm{pH}$ 7.4).

(iv) 表面等离子共振试验. 表面等离子共振(SPR) 试验通过BIAcore ${ }^{\circledR} 3000$ 检测埃可病毒 11 型分别与FcRn 和CD55在 $\mathrm{pH} 7.4$ 和 $\mathrm{pH} 5.5$ 条件下的亲和力, 全程在室温 $25^{\circ} \mathrm{C}$ 完成. 首先, 用于SPR试验的蛋白和病毒都需要换 液于PBST(PBS $+0.005 \%$ Tween-20, pH 7.4)缓冲液中, 将纯化的病毒进行体外生物素化(1 $\mu \mathrm{L}$ biotin/100 $\mu \mathrm{g}$ 病 毒), 室温孵育 $30 \mathrm{~min}$ 后, 浓缩换液到PBST缓冲液中. 将 约6000响应值(RU)的病毒固定在链需亲和素(streptavidin, SA)芯片上, 将FcRn蛋白分别以 1000、500、250、 125、62.5及 $0 \mathrm{nmol} / \mathrm{L}$ 的浓度，CD55蛋白分别以 2000 、 1000、500、250、125及 $0 \mathrm{nmol} / \mathrm{L}$ 的浓度作为流动相流 过芯片. 每个循环后, 用 $4 \mathrm{~mol} / \mathrm{L} \mathrm{NaCl}$ 对芯片表面进行 再生. 对于酸性条件下的亲和力测定, 采用酸性缓冲液
(20 mmol/L MES, $150 \mathrm{mmol} / \mathrm{L} \mathrm{NaCl}$ 和 $0.005 \%$ Tween20, pH 5.5)替代pH 7.4的PBST缓冲液, 其他步骤与中性 条件相同. 最终试验结果通过BIAevaluation ${ }^{\circledR}$ Version 4.1进行分析.

( V ) 冷冻电子显微镜样品制备与数据收集. 埃可 病毒 11 型-CD55/FcRn复合物制备方法如下. 将已纯化 的埃可病毒 11 型颗粒 $(3 \mathrm{mg} / \mathrm{mL})$ 与过量的CD $55 / \mathrm{FcRn}$ 蛋 白分别孵育 $10 \mathrm{~min}$, 然后将复合物样品分别加在附有超 薄碳膜的冷冻铜网(Lacey carbon)上, 吸附 $1 \mathrm{~min}$ 后, 将 铜网表面多余的病毒液用滤纸吸干, 借助Vitrobot Mark IV冷冻制样机器迅速插人液态乙烷中, 后转人液氮中 保存样品. 对于单独病毒(完整病毒、A-颗粒和空壳病 毒颗粒)冷冻样的制备则不需孵育，直接按照相同方法 制样. 酸性条件下的样品制备, 在铜网上吸附 $\mathrm{pH}$ 7.4的 样品后, 用滤纸吸掉铜网表面的多余液体, 再将 $4 \mu \mathrm{L}$ 酸 性缓冲液 (20 mmol/L MES + $150 \mathrm{mmol} / \mathrm{L} \mathrm{NaCl}, \mathrm{pH}$ 5.5) 迅速加在铜网上, $4^{\circ} \mathrm{C}$ 捊育 $5 \mathrm{~min}$ 后, 再进行滤纸吸附和 速冻保存. 数据收集通过装有Folcon III相机的 $300 \mathrm{kV}$ Titan Krios(Thermo Fisher Scientific Inc.)冷冻电子显微 镜完成, 像素尺寸为 $1.09 \AA(1 \AA=0.1 \mathrm{~nm})$, 累计电子剂量 为 $40 \mathrm{e}^{-} / \AA^{2}$, 每张照片分为 39 帧, 欠焦范围为 $-1.5 \sim$ $-2.5 \mu \mathrm{m}$.

(vi) 数据处理与结构解析. 所有的冷冻电子显微 镜原始照片通过MotionCor2程序进行漂移校正 ${ }^{[33]}$. 衬 度传递函数(contrast transfer function, CTF)校正通过 CTFFIND4计算 ${ }^{[34]}$, 使用EMAN2进行颗粒自动挑选 ${ }^{[35]}$, 最终通过Relion ${ }^{[36]}$ 计算得出 10 个结构. 在生理条件下 ( $\mathrm{pH}$ 7.4), 分别得到分辨率为 $2.32 、 2.53 、 3.18 、 2.9$ 和 $2.41 \AA$ 的完整病毒、A-颗粒、空壳病毒、完整病毒CD55复合物和完整病毒-FcRn复合物结构; 在酸性条 件下 (pH 5.5), 分别得到分辨率为 $2.33 、 2.63 、 3.4 、 2.6$ 和2.82 A的完整病毒、A-颗粒、空壳病毒、完整病毒CD55复合物和完整病毒-FcRn复合物结构. 最终分辨 率通过傅里叶壳层关联函数(Fourier shell correlation, FSC)曲线估算得出 ${ }^{[36]}$.

以埃可病毒11型(PDB：1H8T)的晶体结构作为初 始模型, 使用Chimera将晶体结构拟合人完整埃可病毒 11型密度图中 $(\mathrm{pH} 7.4,2.32 \AA)^{[37]}$. 初步拟合后, 在Coot 软件 ${ }^{[38]}$ 中对模型进行手动调整, 以改进密度拟合并更 新序列, 然后通过Phenix对原子模型进一步细化 ${ }^{[39]}$. 所 有模型统计数据(包括键长、键角等)在模型细化过程 中被记录. 经过数轮进一步精修后, 模型坐标在密度图 
中拟合结果良好. 最终模型的立体化学质量通过MolProbity进行评估 ${ }^{[40]}$. 完整病毒-CD55和完整病毒-FcRn 复合物的模型搭建以完整埃可病毒 11 型的结构作为初 始模型, 其过程与上述相似. 最终我们将所有数据的收 集、处理、模型构建等详细信息汇总于表S1 S5. 可视 化密度图和原子模型通过Chimera进行分析, 原子模型 动画使用PyMOL软件进行绘制(http://www.pymol.org).

本研究中得到的 10 个病毒及其复合物结构均已在 电子显微数据库(Electron Microscopy Data Bank, EMDB)以及蛋白数据库(Protein Data Bank, PDB)中注 册登记, 其注册号分别为: $\mathrm{pH}$ 7.4条件下的埃可病毒 11 型完整病毒(EMDB-0854, PDB: 6LA3); pH 5.5条件下 的埃可病毒11型完整病毒(EMDB-0855, PDB: 6LA4); $\mathrm{pH}$ 7.4条件下的埃可病毒 11 型-CD55复合物(EMDB0856, PDB: 6LA5); pH 5.5条件下的埃可病毒11型CD55复合物(EMDB-0859, PDB：6LAO)；pH 7.4条件 下的埃可病毒 11 型-FcRn复合物(EMDB-0857, PDB: $6 \mathrm{LA} 6) ; \mathrm{pH} 5.5$ 条件下的埃可病毒 11 型 $-\mathrm{FcRn}$ 复合物 (EMDB-0858, PDB: 6LA7); pH 7.4条件下的埃可病毒 11型A-颗粒(EMDB-0860, PDB: 6LAP); pH 5.5条件下 的埃可病毒11型A-颗粒(EMDB-0867, PDB: 6LB1); pH 7.4条件下的埃可病毒 11 型空壳病毒(EMDB-0870, PDB: 6LBO); pH 5.5条件下的埃可病毒11型空壳病毒 (EMDB-0871, PDB: 6LBQ).

(vii) 受体修饰的脂质体制备. 脂质体制备参照文 献[41]进行, 将磷脂酰乙醇胺(phosphatidylethanolamine, Sigma)、磷脂酰胆碱(phosphatidylcholine, Sigma)、鞘 磷脂(sphingomyelin, Sigma)、胆固醇(cholesterol, Sigma)、磷脂酸(phosphatidic acid, Sigma) 分别用氯仿溶解 为 $10 \mathrm{mmol} / \mathrm{L}$ 的溶液. 之后将 5 种试剂以摩尔比 1:1:1:1.5:0.3混合于玻璃试管中，再加人 $20 \%(\mathrm{w} / \mathrm{w})$ 镍盐 (1,2-dioleoyl-sn-glycero-3-\{[N-(5-amino-1-carboxypentyl) iminodiacetic acid] succinyl $\}$, Sigma), 然后用旋转蒸 发仪真空蒸干为薄膜状, 后过夜冻干. 最终脂膜按 $3 \mathrm{mg} / \mathrm{mL}$ 的浓度溶于 $\mathrm{pH} 7.4$ 的PBS中, 装人细胞冻存管 后液氮 $/ 37^{\circ} \mathrm{C}$ 水浴反复冻融 10 次，后通过 $0.4 \mu \mathrm{m}$ 薄膜过 滤器 21 个循环, 至此脂质体制备完成. 将脂质体与含 His标签的CD55和FcRn蛋白分别进行室温孵育 $30 \mathrm{~min}$, $\mathrm{CD} 55 / \mathrm{FcRn}$ 终浓度达到 $200 \mu \mathrm{g} / \mathrm{mL}$.

(viii) 脂质体脱壳试验. 具体操作步骤参照文献 $[23,41]$ 进行. 通过蔗糖密度梯度离心得到高纯度成熟 的埃可病毒 11 型, 将受体修饰后脂质体与病毒分别通
过Amicon Ultra-6 $100 \mathrm{kDa}$ 浓缩管换液到酸性缓冲液 $(20 \mathrm{mmol} / \mathrm{L} \mathrm{MES}+150 \mathrm{mmol} / \mathrm{L} \mathrm{NaCl}, \mathrm{pH} 5.5)$ 中, 后将 脂质体与高纯度病毒混合, 终浓度达到 $1.5 \mathrm{mg} / \mathrm{mL}$ 受体 修饰脂质体和 $0.4 \mathrm{mg} / \mathrm{mL}$ 病毒, 迅速放人 $37^{\circ} \mathrm{C}$ 水浴锅孵 育 $15 \mathrm{~min}$. 作为对照, 将含有 $1.5 \mathrm{mg} / \mathrm{mL}$ 脂质体、 $100 \mu \mathrm{g} / \mathrm{mL}$ 牛血清蛋白和 $0.4 \mathrm{mg} / \mathrm{mL}$ 高纯度病毒样品于 $37^{\circ} \mathrm{C}$ 水浴锅孵育 $15 \mathrm{~min}$. 孵育结束后所有样品立刻进 行负染色, 通过FEI Tecnai G2 F20 TWIN TMP透射电 子显微镜于 $200 \mathrm{kV}$ 进行样品成像.

\section{2 结果}

\section{1 埃可病毒11型可与CD55和FcRn在中性和酸性 条件下结合}

为研究埃可病毒 11 型与已发现的埃可等 $\mathrm{B}$ 族肠道 病毒受体FcRn和CD55的相互作用, 分别表达并纯化了 $\mathrm{FcRn}$ 和CD55蛋白可溶的胞外段部分，并用SPR方法检 测了埃可病毒 11 型与这两种蛋白的相互作用(图1).

SPR的结果显示, 埃可病毒 11 型与FcRn和CD55均 可以直接结合. 埃可病毒 11 型病毒颗粒与FcRn在中性 条件下的亲和力为 $339 \mathrm{nmol} / \mathrm{L}$ (图1(a)), 在酸性条件下, 亲和力略有增强, 为 $233 \mathrm{nmol} / \mathrm{L}$ (图1(b)). 埃可病毒 11 型 与 $\mathrm{CD} 55$ 的亲和力比 $\mathrm{FcRn}$ 低, 与 $\mathrm{CD} 55$ 在 $\mathrm{pH}$ 7.4下的亲和 力为 $2.16 \mu \mathrm{mol} / \mathrm{L}$ (图1(c)), 在 $\mathrm{pH} 5.5$ 下为 $1.38 \mu \mathrm{mol} / \mathrm{L}$ (图 1(d)). 试验结果进一步证明了 FcRn和CD55在中性和酸 性条件下均能与埃可病毒 11 型直接结合.

\section{2 埃可病毒11型与CD55和FcRn结合的冷冻电子 显微镜结构}

为进一步研究埃可病毒 11 型与其两个受体, FcRn 和CD55的结合机制和病毒的人侵机制, 我们通过冷冻 电子显微镜技术, 解析了埃可病毒 11 型的完整病毒颗 粒本身, 以及完整病毒与FcRn、CD55的复合物分别在 中性 $(\mathrm{pH}$ 7.4)和酸性 $(\mathrm{pH}$ 5.5)两个孵育条件的冷冻电子 显微镜结构(图2, 图 S1, 表S1 S3). 所解析的 6 个结构均 为原子水平, 其分辨率分别为: 埃可病毒 11 型完整病毒

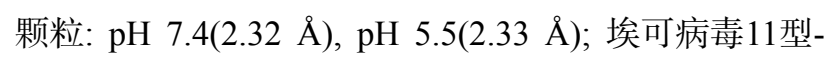
CD55复合物: $\mathrm{pH} 7.4(2.9 \AA), \mathrm{pH} 5.5(2.6 \AA)$; 埃可病毒 11 型-FcRn复合物: $\mathrm{pH} 7.4(2.41 \AA), \mathrm{pH} 5.5(2.82 \AA)$. 在这个 分辨率下, 我们可以清晰地得到病毒表面蛋白和受体 结合的分子细节.

与其他肠道病毒和之前解析的埃可病毒 6 型相同, 

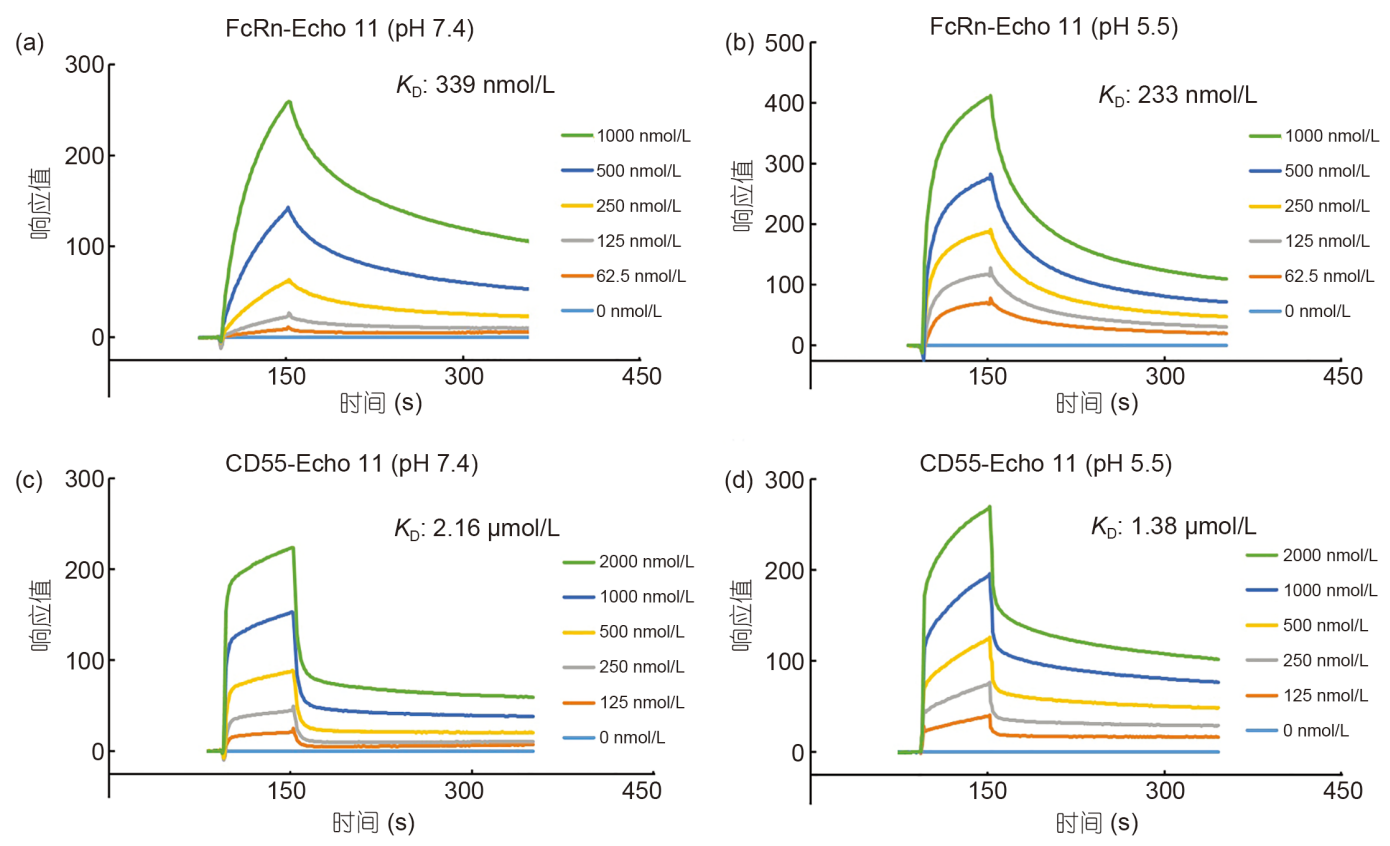

图 $1 \mathrm{FcRn}$ 和CD55可以与埃可病毒11型的病毒颗粒直接结合. 表面等离子共振(SPR)方法检测可溶性FcRn胞外段蛋白与埃可病毒11型的病毒 颗粒在 $\mathrm{pH}$ 7.4(a)和 $\mathrm{pH}$ 5.5(b)条件下的相互作用, 结合 $K_{\mathrm{D}}$ 值如图所示. 表面等离子共振 $(\mathrm{SPR})$ 方法检测可溶性CD55胞外段蛋白与埃可病毒 11 型 的病毒颗粒在 $\mathrm{pH} 7.4(\mathrm{c})$ 和 $\mathrm{pH}$ 5.5(d)条件下的相互作用, 结合 $K_{\mathrm{D}}$ 值如图所示

Figure 1 Echovirus 11 directly binds to FcRn and CD55. BIAcore diagram of Echovirus 11 viral particle bound to FcRn soluble protein at $\mathrm{pH} 7.4$ (a) or pH 5.5 (b), $K_{\mathrm{D}}$ values were shown in the figure. BIAcore diagram of Echovirus 11 viral particle bound to CD55 soluble protein at pH 7.4 (c) or pH 5.5 (d), $K_{\mathrm{D}}$ values were shown in the figure

埃可病毒11型的衣壳由VP1、VP2、VP3和结合在3个 蛋白内部的VP4所构成. 每个病毒颗粒由 60 个VP1、 VP2、VP3 和VP4组成的异源四聚体组成 ${ }^{[23,25]}$. 埃可病 毒11型病毒颗粒在酸性条件下保持稳定，病毒没有发 生变构, 且VP1的“峡谷区”底部仍可以检测到维持病毒 颗粒稳定的脂质分子“口袋因子”(图2(a), (b)). 在埃可病 毒11型和CD55的复合物结构中，病毒颗粒本身的结构 依然保持稳定，“口袋因子”也依然稳定存在于“峡谷 区”底部(图2(c), (d)). 但是与中性条件下的复合物相比 较，酸性条件下的埃可病毒 11 型和CD55的复合物密度 图中, CD55的密度比较差, 说明在酸性条件下, CD55 和埃可病毒 11 型的结合不如在中性条件下稳定，受体 容易脱离病毒. 根据之前的研究结果推测, CD55作为 吸附受体, 主要作用是捕获病毒到细胞表面, 不需要在 酸性条件的内吞体中与病毒结合.

与CD55不同的是，病毒和FcRn结合之后，在中性 和酸性条件下, 病毒颗粒均发生了变构(图2(e), (f)). 受 体FcRn的结合导致了病毒表面蛋白VP1的构象发生了 变化. 与埃可病毒 11 型成熟病毒颗粒、埃可病毒 11 型CD55复合物相比，埃可病毒 11 型-FcRn复合物中“口袋
因子”发生了缺失. “口袋”周围氨基酸的构象变化促使 了“口袋因子”的释放，从而起始了病毒脱衣壳和释放 遗传物质的过程. 与埃可病毒 6 型不同的是, FcRn诱导 埃可病毒 11 型的变构在中性条件下就能发生, 受体-病 毒孵育仅 $10 \mathrm{~min}$ ，就可以导致“口袋因子”的释放．推测 FcRn诱导埃可病毒 11 型发生脱衣壳的效率可能高于埃 可病毒 6 型. 此外，如果不需酸性就可以起始脱衣壳的 话，埃可病毒11型的脱衣壳过程可能会在内吞的早期, 内吞体完成酸化之前就可以起始, 这也与之前埃可病 毒7型上的功能研究结果一致 ${ }^{[42]}$.

\section{3 埃可病毒11型脱衣壳形成的中间态A-颗粒(A- particle)和空壳病毒的冷冻电子显微镜结构}

在埃可病毒 11 型冷冻电子显微镜结构的解析中, 除了成熟病毒颗粒之外，还发现了其他两种形态的病 毒颗粒. 经与其他已解析的肠道病毒结构做对照, 认为 其中一种属于脱衣壳中间态病毒A-颗粒，另一种则是 脱衣壳之后的空壳病毒颗粒(图3, S1, 表S4, S5).

A-颗粒在 $\mathrm{pH} 7.4$ 样品中结构分辨率为 $2.53 \AA, \mathrm{pH}$ 5.5 样品中为 $2.63 \AA$. 这两者之间在结构上无明显区别. 
(a)

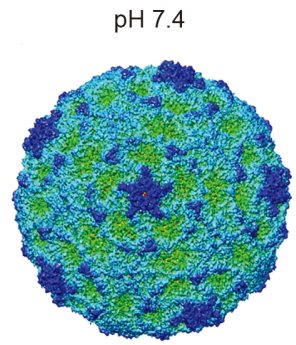

Echo 11
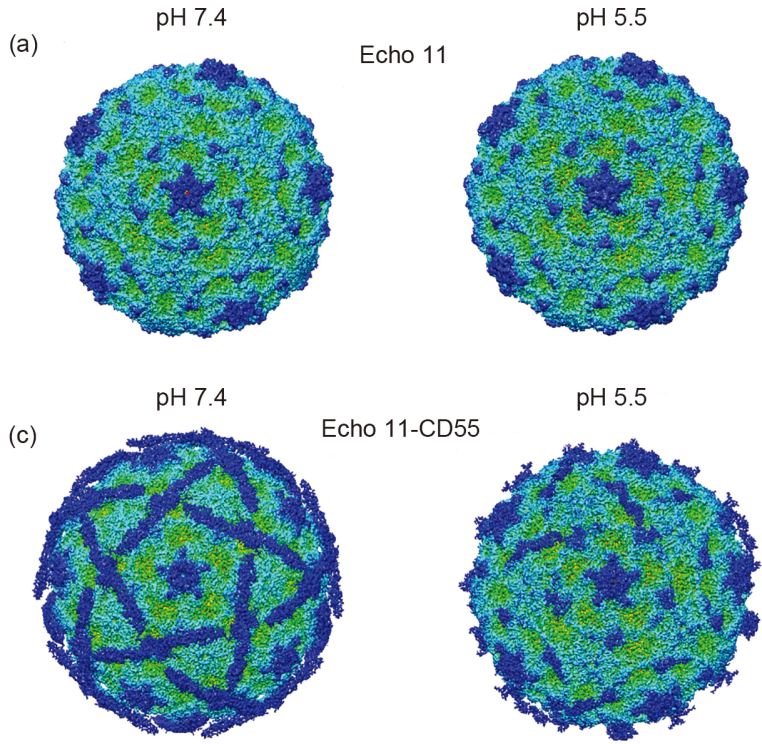

Echo 11-CD55

$\mathrm{pH} 5.5$
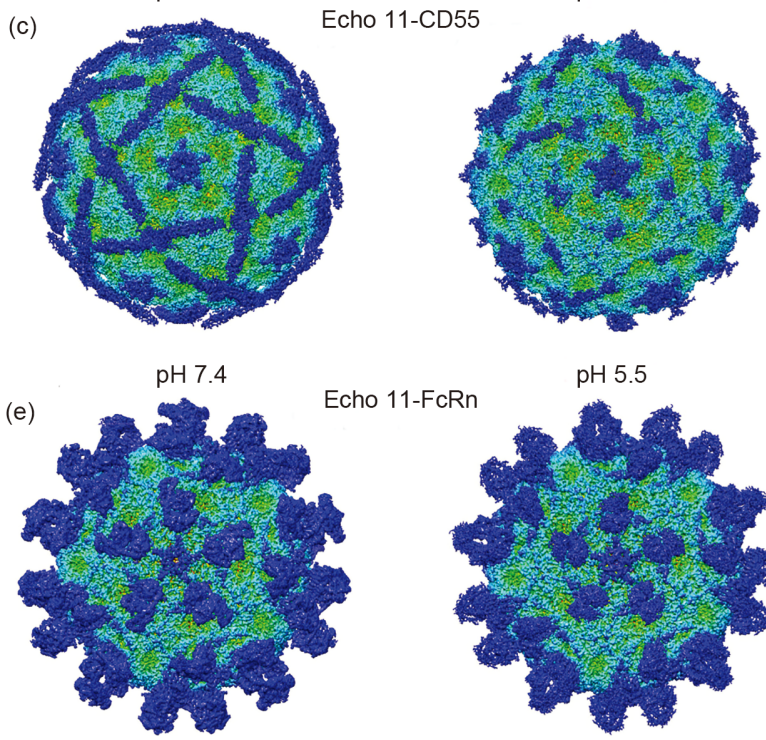

Echo 11-FcRn
$\mathrm{pH} 5.5$

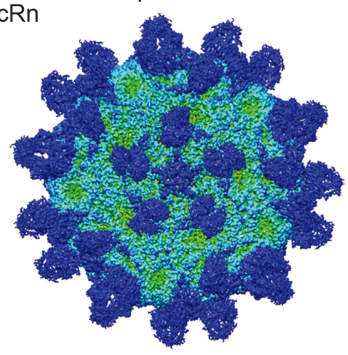

(b)

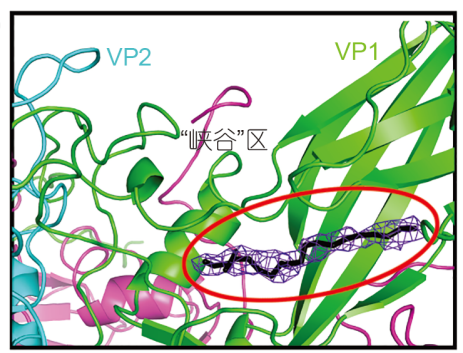

(d)

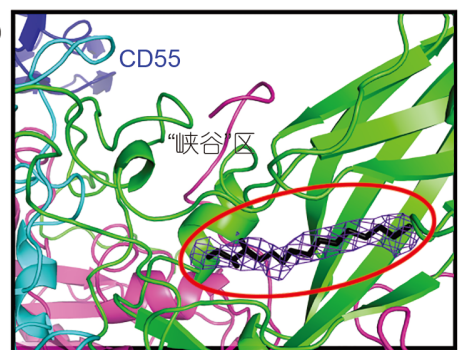

(f)

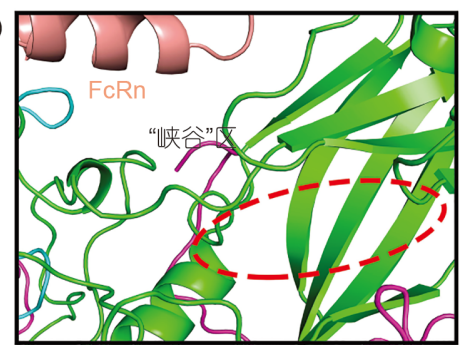

$120130140150160 \AA$

图 2 埃可病毒 11 型, 以及埃可病毒 11 型与其受体CD55和FcRn 的复合物的冷冻电子显微镜结构. (a) 埃可病毒 11 型分别在 $\mathrm{pH} 7.4(2.32 \AA$ )和 $\mathrm{pH}$ $5.5(2.33 \AA)$ 条件下的冷冻电子显微镜结构; (b) 放大显示(a)中疏水口袋及 “口袋因子”部分; (c) 埃可病毒 11 型-CD55复合物分别在pH 7.4(2.9 $)$ 和

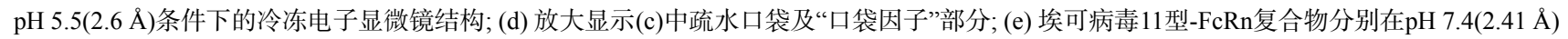
和pH 5.5(2.82 ^)条件下的冷冻电子显微镜结构; (f) 放大显示(e)中疏水口袋部位及参照(b), (d)中“口袋因子”原位置, 显示“口袋因子”已经释放. (a), (c), (e)的冷冻电子显微镜密度图根据半径着色, 如(e)下方图例所示. (b), (d), (f) 丝带模型配色为: 绿色, VP1; 青色, VP2; 紫红色, VP3; 粉橙 色, FcRn大亚基FCGRT; 蓝色, CD55. (b), (d) “口袋因子”显示为黑色棍状图, 以蓝紫色标记出 $1.5 \sigma$ 等高线(contour level)标准检测的电子密度, 并 以红色椭圆形强调显示. (f) “口袋因子”缺失, 同样用 $1.5 \sigma$ 检测不到“口袋因子”的电子密度, 其原有位置用虚线椭圆形显示

Figure 2 Cryo-EM structures of the Echo 11 particles, Echo 11-CD55 and Echo 11-FcRn complexes. (a) The density maps of Echo 11 full particles at pH $7.4(2.32 \AA)$ and pH $5.5(2.33 \AA$ ). (b) The close-up view of the canyon and "pocket" of (a), with the "pocket factor" inside. (c) The density maps of

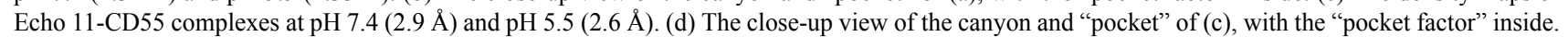
(e) The density maps of Echo 11- FcRn complexes at pH 7.4 (2.41 $\AA$ ) and pH 5.5 (2.82 $\AA$ ). (f) The close-up view of the canyon and "pocket" area of (e), without the "pocket factor". All density maps are colored by radius as shown in the legend under panel (e). Atomic models of proteins are shown in ribbons. In (b) and (d), the "pocket factor" is shown in black sticks. The density map of "pocket factor" presented at $1.5 \sigma$ contour level in purple blue. And the "pocket" area is highlighted by red ovals in close-up views. No density of "pocket factor" can be detected in (f) in the same $1.5 \sigma$ contour level. And the supposed "pocket" area is highlighted by red dashed oval. VP1, VP2, VP3, CD55 and FcRn heavy chain are colored in green, cyan, magenta, salmon and blue, respectively

与完整病毒颗粒相比, A-颗粒的表面会更加松散, 这使 得病毒颗粒的直径比成熟颗粒略有增加. A-颗粒中, VP4蛋白缺失，并且VP1蛋白 $N$ 端的 $1 \sim 59$ 个氨基酸也看 不到明显的电子密度，但病毒颗粒内部还可以看到密 度, 证明病毒颗粒内部的遗传物质尚未释放. 同埃可病 毒11型-FcRn复合物相同，A-颗粒中“峡谷区”底部的位
置也丢失了“口袋因子”，但在该部位的变构程度要大 于埃可病毒 11 型-FcRn复合物.

空壳病毒同样在两种 $\mathrm{pH}$ 的样品中均存在且无明显 区别. 我们详细解析了 $\mathrm{pH}$ 7.4和pH 5.5样品中空壳病毒 结构, 分辨率为 3.18 和 3.4 A. 同样的, 空壳病毒中也缺 失了VP4蛋白和VP1蛋白 $N$ 端部分氨基酸. 但在空壳病 
(a)

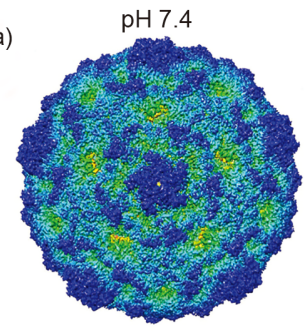

pH 7.4

(c)

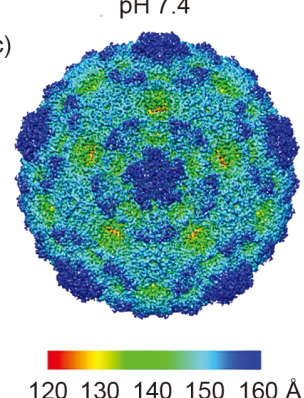

A-颗粒

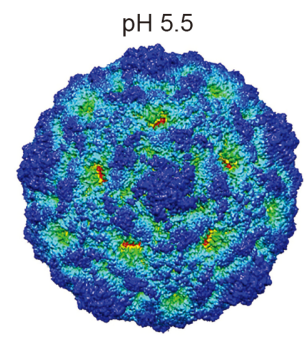

$\mathrm{pH} 5.5$

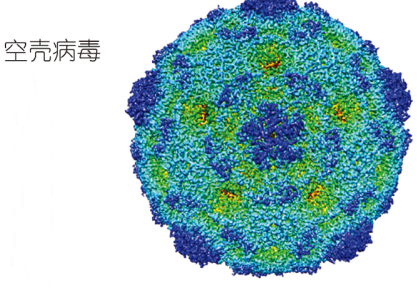

(b)
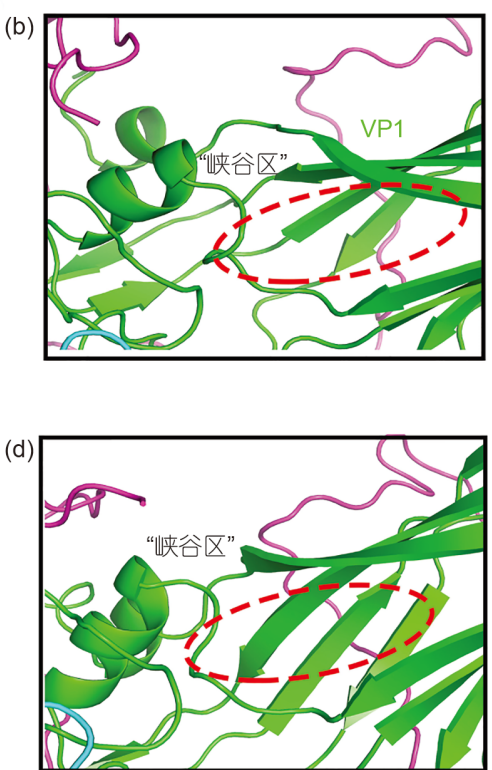

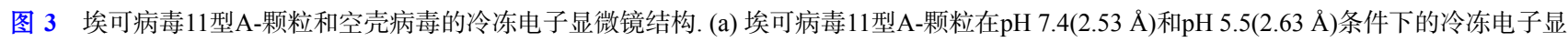
微镜结构; (b) 放大显示(a)中疏水口袋部位; 及参照图2(b)、(d)中“口袋因子”原位置; (c) 埃可病毒 11 型空壳病毒颗粒在pH 7.4(3.18 $\AA$ )和pH 5.5 (3.4 A) 条件下的冷冻电子显微镜结构; (d) 放大显示(c)中疏水口袋部位及参照图2(b)、(d)中“口袋因子”原位置; (a), (c)的冷冻电子显微镜密度图 根据半径着色, 如(c)下方图例所示. (b), (d) 丝带模型配色为: 绿色, VP1; 青色, VP2; 紫红色, VP3. “口袋因子”原有位置用虚线椭圆形显示

Figure 3 Cryo-EM structures of Echo 11 “A-particle” and empty particle. (a) The density maps of Echo 11 “A-particle” at pH 7.4 (2.53 Å) and pH 5.5 $(2.63 \AA)$. (b) The close-up view of the canyon and "pocket" of (a). (c) The density maps of Echo 11 empty particle at pH 7.4 (3.18 $\AA$ ) and pH 5.5 (3.4 $\AA$ ). (d) The close-up view of the canyon and "pocket" of (c). All density maps are colored by radius as shown in the legend under panel (c). Atomic models of proteins are shown in ribbons. The "pocket" area where the "pocket factor" used to be in full particle is highlighted by red dashed ovals in close-up views. VP1, VP2, VP3 are colored in green, cyan and magenta, respectively

毒中, 病毒颗粒内部的核酸和蛋白已经被释放, 只剩残 余的衣壳部分. 同样地，空壳病毒中也丢失了“口袋因 子”. 从埃可病毒 11 型完整病毒颗粒，病毒-FcRn复合 物, A-颗粒, 到空壳病毒. 经过这一系列结构的解析, 我们通过原子/近原子水平的高分辨率冷冻电子显微镜 结构, 解析了病毒整个脱衣壳过程中具代表性的中间 态结构, 详细分析了病毒脱衣壳过程中完整的形态变 化过程：埃可病毒 11 型完整病毒颗粒与脱衣壳受体 FcRn的结合, 使得病毒VP1蛋白“峡谷区”底部的脂质 分子“口袋因子”释放。“口袋因子”的释放打破了病毒 的稳态, 使得病毒VP4蛋白和VP1蛋白的 $N$ 端释放, 形 成A-颗粒. 在此过程中, 也由于VP1的变构, A-颗粒病 毒不再与FcRn受体结合. A-颗粒本身是脱衣壳的中间 态, 并不是稳定的结构. A颗粒中病毒的遗传物质释放, 变为空壳病毒.

\section{4 埃可病毒11型与CD55和FcRn结合位点近原子 水平结构解析}

$\mathrm{FcRn}$ 受体由FCGRT基因表达的大亚基和小亚基 $\beta$
球蛋白 $\left(\beta_{2} \mathrm{~m}\right)$ 所构成. 其中大亚基包含 $\alpha 1, \alpha 2$ 和 $\alpha 3$ 三个结 构域. 在FcRn与埃可病毒 11 型的结合过程中, FcRn大亚 基的 $\alpha 2$ 结构域结合在病毒主要由VP1蛋白构成的“峡 谷”区域. 分别用该结构域的第二和第三个 $\alpha$ 蝶旋与病 毒结合. CD55和埃可病毒11型的结合主要是由CD55 的 $\mathrm{SCR} 3$ 和 $\mathrm{SCR} 4$ 两个结构域与病毒 VP2 和VP3 相互作 用(图4).

\section{5 脂质体模型试验证实低 $\mathrm{pH}$ 条件下FcRn诱导 脱衣壳}

为进一步证明 $F \mathrm{cRn}$ 可以诱导埃可病毒 11 型完成脱 衣壳过程, 利用分别在表面用 $F \mathrm{CRn}$ 和CD55修饰的脂质 体, 模拟膜上的受体结构. 脂质体在制作过程中加人了 镍离子, 可以与FcRn或CD55可溶性蛋白的His标签结 合, 将受体可溶性蛋白绑定在脂质体表面, 从而形成一 个模拟膜蛋白的结构. 我们将结合了受体的脂质体与 埃可病毒 11 型的病毒颗粒在 $37^{\circ} \mathrm{C}, \mathrm{pH} 5.5$ 的模拟生理 条件下捊育, 并通过负染透射电子显微镜检测睬育后 病毒的形态变化(图5). 
(a)

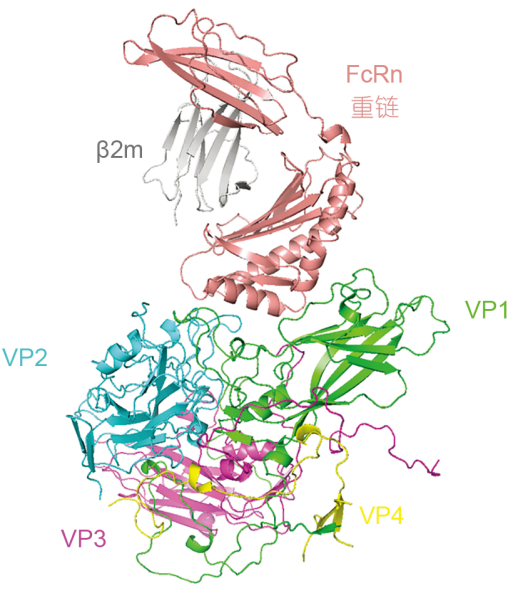

(b)

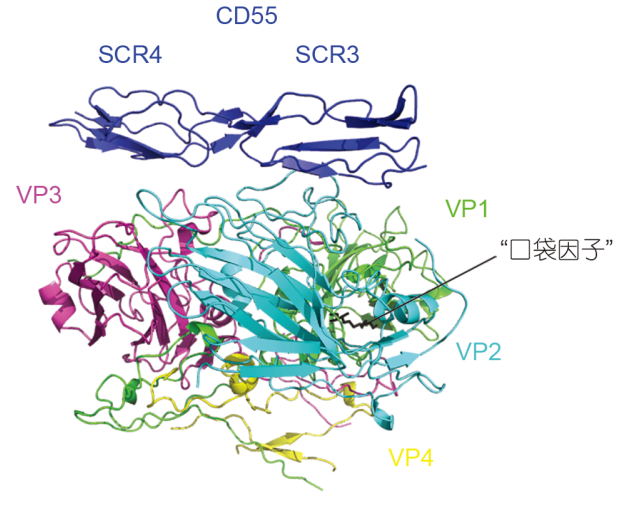

图 4 埃可病毒11型和FcRn、CD55结合的结构基础. (a) 埃可病毒11型与FcRn的结合机制. 图示病毒衣壳一个异源四聚体单位(VP1-4)与单个 FcRn异源二聚体分子结合方式. (b) 埃可病毒11型与CD55的结合机制. 图示病毒衣壳一个异源四聚体单位(VP1-4)与单个CD55分子结合方式. 绿色, VP1; 青色, VP2; 紫红色, VP3; 黄色, VP4; 玫瑰金色, FcRn大亚基FCGRT; 银灰色, FcRn小亚基 $\beta_{2} \mathrm{~m}$; 蓝色, CD55

Figure 4 The structural basis of the interactions between Echovirus 11 and FcRn/CD55 receptors. (a) The binding mechanism between Echovirus 11 and FcRn at pH 7.4. Shown in one asymmetric unit. (b) The binding mechanism of Echovirus 11 and CD55 at pH 7.4. Shown in one asymmetric unit. The proteins are represented as ribbon models and colored by chains. Green, VP1; cyan, VP2; fuchsia, VP3; yellow, VP4; rose gold, FCGRT; silver gray, $\beta_{2} \mathrm{~m}$; blue, CD55. The "pocket factor" is shown as black stick

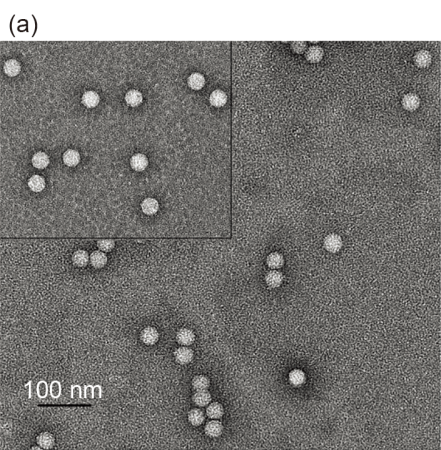

(d)

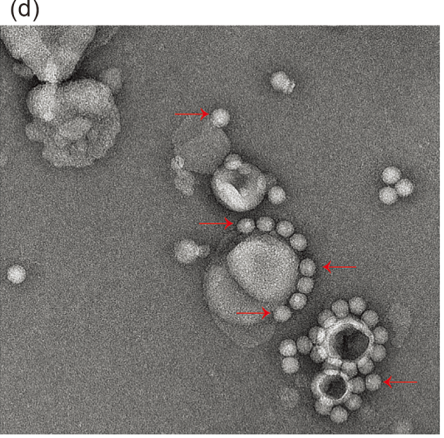

(b)

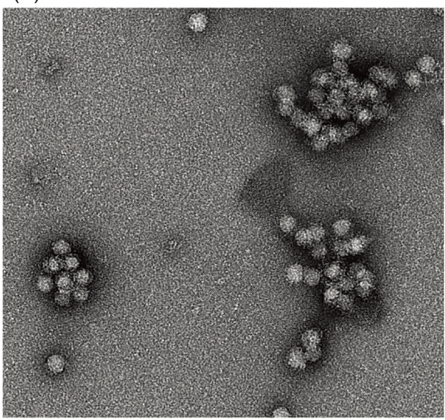

(e)

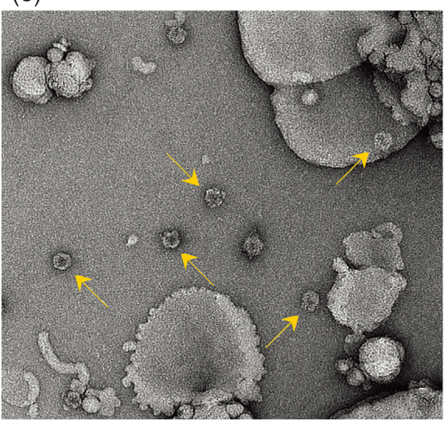

(c)

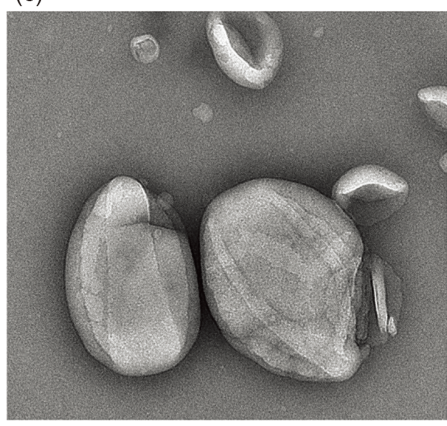

(f)

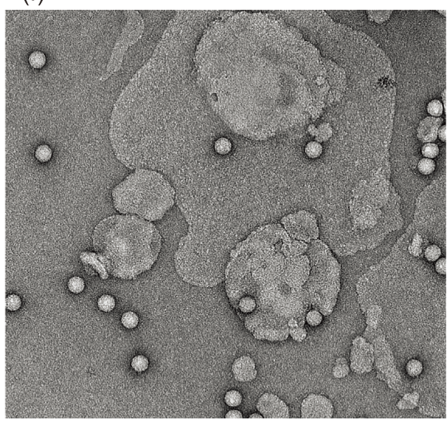

图 5 表面结合了 $\mathrm{FcRn}$ 的脂质体可以诱导埃可病毒 11 型脱衣壳. 图示负染透射电子显微镜检测结果. 所有样品均为在 $37^{\circ} \mathrm{C}, \mathrm{pH} 5.5$ 条件下捊育 $15 \mathrm{~min}$ 后, 负染制样, 透射电子显微镜检测结果. 比例尺所示为 $100 \mathrm{~nm}$. (a) 埃可病毒 11 型的病毒颗粒(左上)和埃可病毒 11 型-CD55复合物; (b) 埃 可病毒11型-FcRn复合物; (c) 未结合受体的脂质体; (d) 埃可病毒11型与结合了CD55的脂质体共同孵育, 红色箭头所示为结合在脂质体表面的 病毒颗粒; (e) 埃可病毒11型与结合了 FcRn的脂质体共同捊育, 黄色箭头所示为脱衣壳之后的空壳病毒; (f) 埃可病毒 11 型与未结合受体的脂质 体共同孵育对照

Figure 5 Echo 11 incubation with receptor-decorated liposomes. All samples were incubated for $15 \mathrm{~min}$ at $37^{\circ} \mathrm{C}$, $\mathrm{pH} 5.5$. The results of negative staining EM detection were shown. The scale bar represents $100 \mathrm{~nm}$. (a) Echo 11 full particles (upper left) and Echo 11-CD55 complexes. (b) Echo 11FcRn complexes. (c) Nickel-charged liposomes (without receptor). (d) Echo 11 incubated with CD55-decorated liposomes. The particles that attached to the surface of the liposomes were indicated by red arrows. (e) Echo 11 incubated with FcRn-decorated liposomes. Empty particles were indicated by yellow arrows. (f) Echo 11 incubated with nickel-charged liposomes without receptor decoration 
负染结果显示, 纯化病毒颗粒和病毒-CD55复合物 在 $37^{\circ} \mathrm{C}, \mathrm{pH} 5.5$ 条件下没有明显变构(图5(a))，病毒与 FcRn在孵育后发生了聚集(图5(b)). 病毒颗粒可以结合 在修饰了CD55的脂质体表面，但病毒颗粒没有发生变 构(图5(d)). 病毒颗粒可以结合在修饰了 FcRn的脂质体 表面, 但在与修饰了 FcRn的脂质体共同孵育之后, 病毒 发生变构, 产生了空壳病毒. 并且病毒脱衣壳变成空壳 之后, 会从脂质体表面脱落(图5(e)). 对照显示了未经受 体蛋白修饰的脂质体形态(图5(c)), 病毒颗粒不与未结 合受体的脂质体直接结合(图5(f)). 试验证明了 FcRn可 以在膜结构的帮助下，诱导埃可病毒11型完成脱衣壳， FcRn是埃可病毒 11 型的脱衣壳受体.

\section{3 结论与讨论}

\section{1 埃可病毒11型利用“双受体系统”入侵细胞的 机制}

在本项研究中解析了埃可病毒 11 型的3种病毒颗 粒: 成熟病毒颗粒、A-颗粒和空壳病毒颗粒; 以及埃可 病毒 11 型与它的两个受体CD55和FcRn的复合物, 在中 性和酸性两种 $\mathrm{pH}$ 条件下的复合物结构。这10个原子或 近原子水平高分辨率冷冻电子显微镜结构展示了病毒 人侵过程的各个状态，系统地显示了病毒人侵的整个 过程(图6).

肠道病毒人侵时，首先结合在细胞表面，随后内

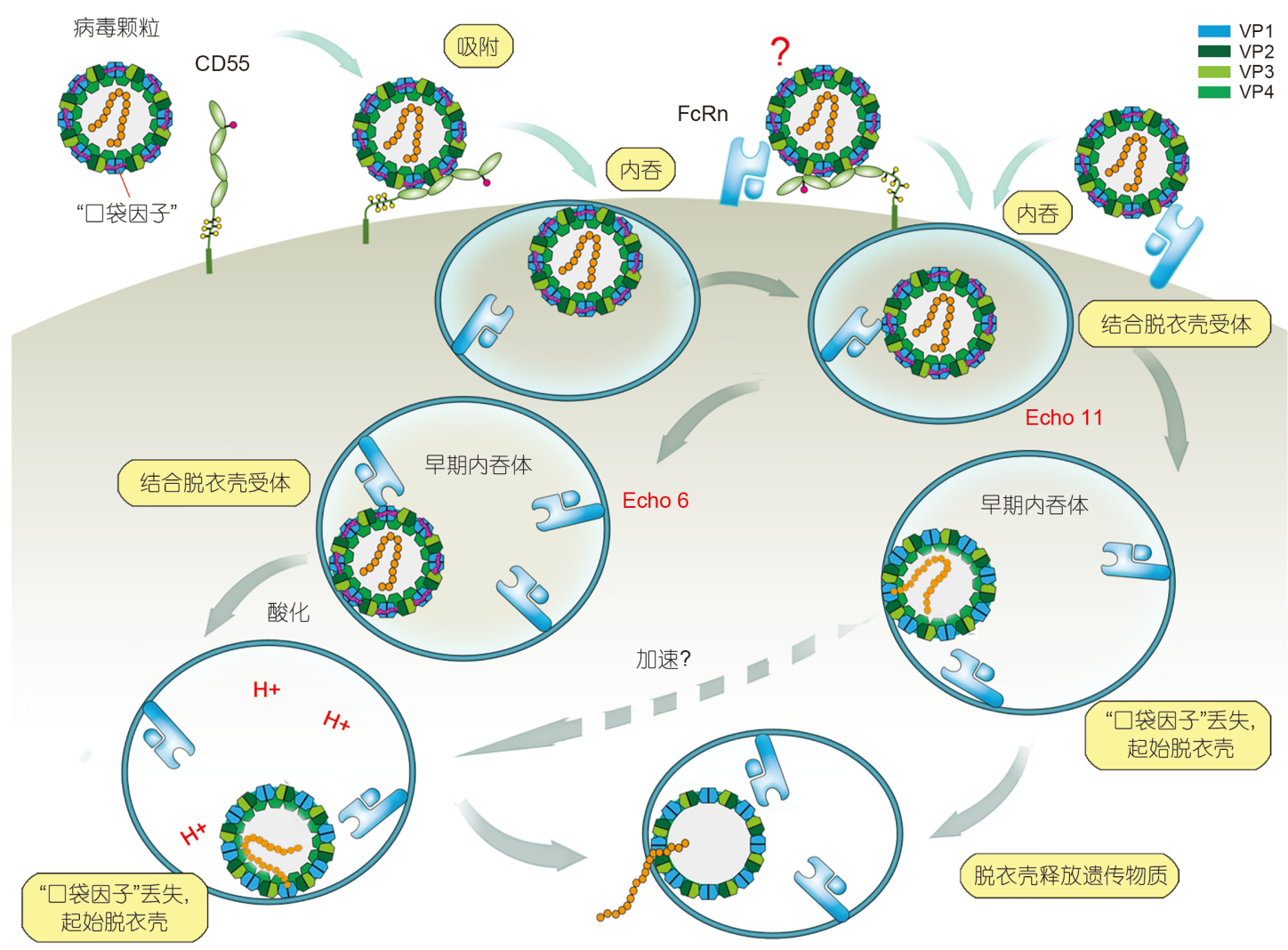

图 6 埃可病毒侵染的细胞与分子机制模型. 模型图片根据文献[23]修改. 组成埃可病毒衣壳的4种结构蛋白(VP1、VP2、VP3和VP4)分别以蓝 色、深橄榄绿色、青草绿色和叶绿色表示. VP1中“口袋因子”以紫红色代示. 病毒RNA以橙色表示. 两种受体CD55和FcRn分别以浅绿和天蓝色 表示. 问号显示为可能存在, 目前尚未经过试验证实的机制. 在新的模型中, 埃可病毒 11 型在与FcRn结合之后, “口袋因子”可以在早期内吞体的 生理pH下迅速释放. 而埃可病毒6型的“口袋因子”释放发生在内吞体继续酸化的条件下. 模型图片使用已取得Elsevier授权 ${ }^{[23]}$

Figure 6 Model of echovirus entry into the cell. This model is a modification based on Ref. [23]. The four structural proteins (VP1, VP2, VP3 and VP4) comprising of viral capsid are indicated in blue, dark olive green, forest green, and pigment green, respectively. Magenta kinked line on VP1 indicates the "pocket factor" (this is the key focal point for the difference between Echovirus 6 in Ref. [23] and Echovirus 11 in this paper). The viral RNA genome is shown in orange. CD55 and FcRn are displayed in light green and sky blue, respectively. The possible double receptor binding modes on the viral surface are labeled with question marks as it has not been confirmed. In this new model, the "pocket factor" of Echovirus 11 was released at physiological $\mathrm{pH}$ after binding to FcRn but Echovirus 6 releases its "pocket factor" only at low pH. Low pH may accelerate the genome-release process for Echovirus 11 but not necessary. Reprinted from Ref. [23], Copyright (2019) with permission from Elsevier 
吞进人内吞体, 脱衣壳释放遗传物质的过程通常在酸 性的内吞体中进行 ${ }^{[3,23,27]}$. 本研究结果显示, 埃可病毒 11 型在细胞表面, 首先可以和吸附受体CD55结合. 与 CD55的结合并不引起病毒的变构, 病毒通过内吞作 用进人内吞体. 根据之前的研究结果显示, FcRn同样 可以介导埃可病毒 11 型在细胞表面的结合 ${ }^{[24]}$. 内吞过 程是否需要 $F c R n$ 的介导则需要进一步试验证明. 在内 吞体中, 病毒和脱衣壳受体FcRn结合, 并由FcRn诱导 病毒变构. 首先是结合在VP1“峡谷区”底部, 维持病毒 衣壳结构稳定的“口袋因子”的释放. “口袋因子”的释 放使得病毒进一步变构, 受体脱离病毒表面, 衣壳蛋 白VP4和VP1的 $N$ 端释放, 形成A-颗粒. 根据在肠道病 毒脊髓灰质炎病毒中的研究, 病毒的 VP4 和VP 1 的 $N$ 端在内吞体膜上形成“孔道”, 从而使遗传物质得以释 放到内吞体外胞质中 ${ }^{[41]}$. 在A-颗粒中, 遗传物质尚未 释放, 但检测不到 VP4, 以及 VP1的 $N$ 端 59 个氨基酸的 密度. 最终, 遗传物质释放后会形成空壳病毒, 空壳病 毒在 A-颗粒的基础上, 进一步缺失了内部的遗传 物质.

\section{2 埃可病毒 11 型的受体结合与人侵机制和埃可病 毒6型的异同}

埃可病毒 11 型与 CD55的结合主要是用CD55的 SCR3、SCR4结构域与病毒的VP2、VP3结合，与埃可 病毒 6 型的结合位置和结合模式均不相同, 与埃可病毒
12型的结合位置相同, 与埃可病毒 7 型的结合位置相 似 ${ }^{[23]}$. 在这个结合位置, 与FcRn所结合的VP1的“峡谷 区”位置没有重叠, 并且脱衣壳受体结合引起的变构也 不会对结合造成影响 ${ }^{[23]}$.

埃可病毒 11 型与埃可病毒 6 型均使用CD 55 和 FcRn 两种受体完成病毒的人侵过程 ${ }^{[23]}$. 其中CD55作为细胞 表面的吸附受体, 不诱导病毒颗粒的变构, 而FcRn作为 脱衣壳受体, 诱导病毒的脱衣壳和释放遗传物质的过 程. 埃可病毒 11 型与 FcRn的亲和力与埃可病毒 6 型相 似, 但是CD55的亲和力与之相比低大约一个数量级. 因此对于埃可病毒 11 型来说, 在细胞表面同样存在 CD55和FcRn两个受体的情况下, 与FcRn结合的亲和力 会更高. 但在细胞表面CD55表达量远高于FcRn的情况 下, 如293T细胞中 ${ }^{[23]}$, 可以使用CD55将病毒吸附到细 胞表面, 这对于提高病毒的感染效率仍然有着重要的 意义.

此外, FcRn诱导埃可病毒 11 型脱衣壳的效率在 $4^{\circ} \mathrm{C}$ 和中性 $\mathrm{pH}$ 条件下要高于埃可病毒 6 型. 病毒与 $\mathrm{FcRn}$ 中 性条件下, $4^{\circ} \mathrm{C}$ 孵育 $10 \mathrm{~min}$, 埃可病毒 6 型未发生变构, 需要酸性条件诱导才能起始变构和脱衣壳过程 ${ }^{[23]}$. 但 是在同样条件下，埃可病毒 11 型则不需要酸性条件的 促进作用就已经完成了“口袋因子”的释放, 起始了变 构过程. 推测埃可病毒11型的脱衣壳效率可能更高, 并 且脱衣壳可能在内吞之后发生的更快, 不需要经过内 吞体的酸化作用. 但是, 酸化过程可能加速脱衣壳.

致谢感谢斯坦福大学生物工程系张凯铭和中国科学院微生物研究所病原微生物与免疫学重点实验室璩骁、王庆玲、宋 豪、齐建勋老师在本项研究中提供的帮助。感谢南方科技大学冷冻电镜中心在冷冻电子显微镜方面的技术支持, 中国 科学院动物研究所膜生物学国家重点实验室夏鹏雁老师在冷冻与透射电子显微镜操作方面的支持, 以及中国科学院微 生物研究所大型仪器中心焚铮老师在SPR方面的支持.

\section{参考文献}

1 Gao G F. From “A”IV to “Z”IKV: Attacks from emerging and re-emerging pathogens. Cell, 2018, 172: 1157-1159

2 Abzug M J. The enteroviruses: Problems in need of treatments. J Infection, 2014, 68: S108-S114

3 Tuthill T J, Groppelli E, Hogle J M, et al. Picornaviruses. Curr Top Microbiol Immunol, 2010, 343: 43-89

4 Huang Y, Zhou Y, Lu H, et al. Characterization of severe hand, foot, and mouth disease in Shenzhen, China, 2009-2013. J Med Virol, 2015, 87: 1471-1479

5 Khetsuriani N, Lamonte-Fowlkes A, Oberst S, et al. Enterovirus surveillance-United States, 1970-2005. MMWR Surveill Summ, 2006, 55: 1-20

6 Chen Q J, Cao C Y, Zhang Y F, et al. Genetic analysis of echovirus 11 isolated from patients with viral encephalitis in Longyan, China (in Chinese). Chin J Virol, 2015, 31: 36-41 [陈前进, 曹春远, 张彦锋, 等. 病毒性脑炎病例中埃可病毒11型病毒的基因特征分析. 病毒学报, 2015, 31: 3641]

7 Abedi G R, Watson J T, Nix W A, et al. Enterovirus and parechovirus surveillance-United States, 2014-2016. MMWR Morb Mortal Wkly Rep, 2018, 67: 515-518

8 Chen J H, Chiu N C, Chang J H, et al. A neonatal echovirus 11 outbreak in an obstetric clinic. J Microbiol Immunol Infect, 2005, 38: 332-337 
9 Berry P J, Nagington J. Fatal infection with echovirus 11. Arch Dis Child, 1982, 57: 22-29

10 Modlin J F. Fatal echovirus-11 disease in premature neonates. Pediatrics, 1980, 66: 775-780

11 Li J, Yan D M, Chen L, et al. Multiple genotypes of Echovirus 11 circulated in mainland China between 1994 and 2017. Sci Rep, 2019, 9: 1-8

12 Somekh E, Shohat T, Handsher R, et al. An outbreak of echovirus 11 in a children's home. Epidemiol Infect, 2001, 126: 441-444

13 Yamayoshi S, Yamashita Y, Li J, et al. Scavenger receptor B2 is a cellular receptor for enterovirus 71. Nat Med, 2009, 15: 798-801

14 Nishimura Y, Shimojima M, Tano Y, et al. Human P-selectin glycoprotein ligand-1 is a functional receptor for enterovirus 71. Nat Med, 2009, 15: 794-797

15 Staring J, van den Hengel L G, Raaben M, et al. KREMEN1 is a host entry receptor for a major group of enteroviruses. Cell Host Microbe, 2018, 23: 636-643.e5

16 Mendelsohn C L, Wimmer E, Racaniello V R. Cellular receptor for poliovirus: Molecular cloning, nucleotide sequence, and expression of a new member of the immunoglobulin superfamily. Cell, 1989, 56: 855-865

17 Xiao C, Bator C M, Bowman V D, et al. Interaction of coxsackievirus A21 with its cellular receptor, ICAM-1. J Virol, 2001, 75: 2444-2451

18 Baggen J, Hurdiss D L, Zocher G, et al. Role of enhanced receptor engagement in the evolution of a pandemic acute hemorrhagic conjunctivitis virus. Proc Natl Acad Sci USA, 2018, 115: 397-402

19 Wei W, Guo H, Chang J, et al. ICAM-5/Telencephalin is a functional entry receptor for Enterovirus D68. Cell Host Microbe, 2016, 20: 631-641

20 Bergelson J M, Chan M, Solomon K R, et al. Decay-accelerating factor (CD55), a glycosylphosphatidylinositol-anchored complement regulatory protein, is a receptor for several echoviruses. Proc Natl Acad Sci USA, 1994, 91: 6245-6248

21 Ward T, Pipkin P A, Clarkson N A, et al. Decay-accelerating factor CD55 is identified as the receptor for echovirus 7 using CELICS, a rapid immuno-focal cloning method. EMBO J, 1994, 13: 5070-5074

22 Bergelson J M, Cunningham J A, Droguett G, et al. Isolation of a common receptor for Coxsackie B viruses and adenoviruses 2 and 5. Science, 1997, 275: 1320-1323

23 Zhao X, Zhang G, Liu S, et al. Human neonatal Fc receptor is the cellular uncoating receptor for Enterovirus B. Cell, 2019, 177: 1553-1565.e16

24 Morosky S, Wells A I, Lemon K, et al. The neonatal Fc receptor is a pan-echovirus receptor. Proc Natl Acad Sci USA, 2019, 116: 3758-3763

25 Rossmann M G, He Y, Kuhn R J. Picornavirus-receptor interactions. Trends Microbiol, 2002, 10: 324-331

26 He Y, Lin F, Chipman P R, et al. Structure of decay-accelerating factor bound to echovirus 7: A virus-receptor complex. Proc Natl Acad Sci USA, 2002, 99: 10325-10329

27 Bergelson J M, Coyne C B. Picornavirus entry. Adv Exp Med Biol, 2013, 790: 24-41

28 Bubeck D, Filman D J, Hogle J M. Cryo-electron microscopy reconstruction of a poliovirus-receptor-membrane complex. Nat Struct Mol Biol, 2005, 12: 615-618

29 Zhang P, Mueller S, Morais M C, et al. Crystal structure of CD155 and electron microscopic studies of its complexes with polioviruses. Proc Natl Acad Sci USA, 2008, 105: 18284-18289

30 Strauss M, Filman D J, Belnap D M, et al. Nectin-like interactions between poliovirus and its receptor trigger conformational changes associated with cell entry. J Virol, 2015, 89: 4143-4157

31 Organtini L J, Makhov A M, Conway J F, et al. Kinetic and structural analysis of coxsackievirus B3 receptor interactions and formation of the Aparticle. J Virol, 2014, 88: 5755-5765

32 Xiao C, Bator-Kelly C M, Rieder E, et al. The crystal structure of coxsackievirus A21 and its interaction with ICAM-1. Structure, 2005, 13: 10191033

33 Zheng S Q, Palovcak E, Armache J P, et al. MotionCor2: Anisotropic correction of beam-induced motion for improved cryo-electron microscopy. Nat Methods, 2017, 14: 331-332

34 Rohou A, Grigorieff N. CTFFIND4: Fast and accurate defocus estimation from electron micrographs. J Struct Biol, 2015, 192: 216-221

35 Tang G, Peng L, Baldwin P R, et al. EMAN2: An extensible image processing suite for electron microscopy. J Struct Biol, 2007, 157: 38-46

36 Scheres S H W. RELION: Implementation of a Bayesian approach to cryo-EM structure determination. J Struct Biol, 2012, 180: 519-530

37 Pettersen E F, Goddard T D, Huang C C, et al. UCSF Chimera? A visualization system for exploratory research and analysis. J Comput Chem, 2004, 25: 1605-1612

38 Emsley P, Lohkamp B, Scott W G, et al. Features and development of Coot. Acta Crystlogr D Biol Crystlogr, 2010, 66: 486-501

39 Adams P D, Afonine P V, Bunkóczi G, et al. PHENIX: A comprehensive Python-based system for macromolecular structure solution. Acta Crystlogr D Biol Crystlogr, 2010, 66: 213-221

40 Chen V B, Arendall Iii W B, Headd J J, et al. MolProbity: All-atom structure validation for macromolecular crystallography. Acta Crystlogr D Biol Crystlogr, 2010, 66: 12-21

41 Strauss M, Levy H C, Bostina M, et al. RNA transfer from poliovirus $135 \mathrm{~S}$ particles across membranes is mediated by long umbilical connectors. J Virol, 2013, 87: 3903-3914 
42 Kim C, Bergelson J M. Echovirus 7 entry into polarized intestinal epithelial cells requires clathrin and Rab7. mBio, 2012, 3: e00304-11

\section{补充材料}

图S1 冷冻电子显微镜密度图的分辨率评估

表S1 两种pH条件(pH 7.4/pH 5.5)下, 埃可病毒11型完整病毒颗粒的冷冻电子显微镜数据的收集、修正以及验证统计

表S2 两种pH条件(pH 7.4/pH 5.5)下, 埃可病毒11型-CD55复合物的冷冻电子显微镜数据的收集、修正以及验证统计

表S3 两种pH条件(pH 7.4/pH 5.5)下, 埃可病毒11型-FcRn复合物的冷冻电子显微镜数据的收集、修正以及验证统计

表S4 两种pH条件(pH 7.4/pH 5.5)下, 埃可病毒11型A-颗粒的冷冻电子显微镜数据的收集、修正以及验证统计

表S5 两种 $\mathrm{pH}$ 条件( $\mathrm{pH}$ 7.4/pH 5.5)下, 埃可病毒11型空壳病毒的冷冻电子显微镜数据的收集、修正以及验证统计

本文以上补充材料见网络版csb.scichina.com. 补充材料为作者提供的原始数据, 作者对其学术质量和内容负责. 


\title{
Molecular and structural basis of Echovirus 11 infection by using the dual-receptor system of CD55 and FcRn
}

\author{
Sheng $\mathrm{Niu}^{1,2 \dagger}$, Chuang $\mathrm{Liu}^{3 \dagger}$, Congcong Liu ${ }^{3}$, Sheng Liu ${ }^{2,5}$, Yang Song ${ }^{6}$, Yong Zhang ${ }^{6,7}$, Wenxia Tian ${ }^{1}$, \\ Xin Zhao ${ }^{2,4^{*}}$, Peiyi Wang ${ }^{3 *}$ \& George F. Gao ${ }^{2,4,6^{*}}$ \\ ${ }^{1}$ College of Animal Science and Veterinary Medicine, Shanxi Agricultural University, Taigu 030801, China; \\ ${ }^{2}$ CAS Key Laboratory of Pathogenic Microbiology and Immunology, Institute of Microbiology, Chinese Academy of Sciences (CAS), Beijing 100101, \\ China; \\ ${ }^{3}$ SUSTech Cryo-EM Facility Center, Department of Biology, Southern University of Science and Technology, Shenzhen 518055, China; \\ ${ }^{4}$ Center for Influenza Research and Early-Warning (CASCIRE), Chinese Academy of Sciences, Beijing 100101, China; \\ ${ }^{5}$ School of Life Sciences, University of Science and Technology of China, Hefei 230026, China; \\ ${ }^{6}$ National Institute for Viral Disease Control and Prevention, Chinese Center for Disease Control and Prevention (China CDC), Beijing 102206, China, \\ ${ }^{7}$ WHO WPRO Regional Polio Reference Laboratory, NHC Key Laboratory of Biosafety, National Institute for Viral Disease Control and Prevention, \\ Chinese Center for Disease Control and Prevention, Beijing 102206, China \\ $\dagger$ These authors contributed equally to this work \\ * Corresponding authors, E-mail: zhaoxin@im.ac.cn; wangpy@sustech.edu.cn; gaof@im.ac.cn
}

Echovirus 11 (Echo 11) is a serotype of Enterovirus B (EV-B) belonging to the genus Enterovirus in the family Picornaviridae. Echo 11 infections are associated with viral encephalitis (VE), viral meningitis (VM), and viral meningoencephalitis (VME). Echo 11 was reported to cause severe illnesses in neonates or infants, with high morbidity and mortality. In addition, Echo 11 has frequently been identified as the causative agent of outbreaks, greatly threatens public health. For example, in early 2019, an Echo 11 outbreak occurred in a hospital of Guangdong Province in China, leading to nineteen infections of newborns and five of them died. CD55 has been designated an attaching receptor of several echoviruses in the 1990s. But CD55 alone is unable to help the virus to complete its whole entry process. In our earlier work, we found that the human neonatal Fc receptor (FcRn) is the cellular uncoating receptor for Enterovirus B and illustrated the entry mechanism taking Echo 6 as an example. We proposed the coordination of attaching and uncoating "dual-receptor system" in the entry pathways.

Here, we analyzed 10 cryo-electron microscopy (Cryo-EM) structures of Echo 11 viral particles in three different forms (free, "A-particle" and empty particle), and Echo 11 in complex with receptor CD55 or FcRn, under both neutral (pH 7.4) and acidic ( $\mathrm{pH}$ 5.5) conditions. With atomic or near-atomic resolutions (2.32-3.4 $\AA$ ), we obtained detailed characterization of the molecular events during Echo 11 entry. The structures revealed that CD55 is the attaching receptor of Echo 11, which facilitates the viral attachment to cell surface. Similar to Echo 12 and Echo 7, Echo 11 uses its VP2 and VP3 domain to bind short consensus repeat (SCR) module SCR 3 and SCR4 domains of CD55. FcRn is the uncoating receptor, which uses the $\alpha 2$ domain of its heavy chain FCGRT to insert into and bind the "canyon" of Echo 11 VP1 domain. The binding induced the extrusion of "pocket factor" and resulted in virus uncoating and genome release. FcRn induced Echo 11 viral particle conformational change and "pocket factor" release started at neutral $\mathrm{pH}$, which is different from Echo 6, there the "pocket factor" release occurs at low $\mathrm{pH}$. This hints us that acidic treatment might not be an essential requirement for the uncoating of all Enterovirus B which uses FcRn as their uncoating receptor. The uncoating process is able to start in early endosomes. SPR (Surface plasmon resonance) analysis certified that, Echo 11 can bind to both receptors, but has a higher affinity with FcRn than to CD55. FcRn-mediated Echo 11 uncoating was further confirmed with an FcRn-decorated liposome model, which induced the structural transitions of Echo 11 into empty particles. This work provided a molecular and structural basis for our understanding of the mechanisms of Echo 11 entry. And it is an important progress in dissecting the mechanism of the "dual-receptor system" in non-enveloped virus entry.

echovirus 11, enterovirus, cryo-electron microscopy (Cryo-EM), entry, dual-receptor system, CD55, FcRn doi: 10.1360/TB-2019-0786 